\title{
How Urban Storm- and Wastewater Management Prepares for Emerging Opportunities and Threats: Digital Transformation, Ubiquitous Sensing, New Data Sources, and Beyond-A Horizon Scan
}

Frank Blumensaat, ${ }^{\dagger, \dagger(0)}$ João P. Leitão, ${ }^{\dagger}$ Christoph Ort, ${ }^{*},{ }^{\dagger}$ Jörg Rieckermann, ${ }^{\dagger}$ Andreas Scheidegger, ${ }^{\dagger}$ Peter A. Vanrolleghem, ${ }^{\S, \|}$ and Kris Villez ${ }^{\dagger}$

${ }^{\dagger}$ Eawag, Swiss Federal Institute of Aquatic Science and Technology, Überlandstrasse 133, 8600 Dübendorf, Switzerland

${ }^{ \pm}$Institute of Environmental Engineering, Chair of Urban Water Systems, ETH Zurich, Stefano-Franscini-Platz 5, 8093 Zurich, Switzerland

${ }^{\S}$ modelEAU, Université Laval, Département de génie civil et de génie des eaux, 1065 av. de la Médecine, Québec, Québec G1 V 0A6, Canada

"CentrEau, Université Laval, 1065 av. de la Médecine, Québec, Québec G1 V 0A6, Canada

Supporting Information

ABSTRACT: Ubiquitous sensing will create many opportunities and threats for urban water management, which are only poorly understood today. To identify the most relevant trends, we conducted a horizon scan regarding how ubiquitous sensing will shape the future of urban drainage and wastewater management. Our survey of the international urban water community received an active response from both the academics and the professionals from the water industry. The analysis of the responses demonstrates that emerging topics for urban water will often involve experts from different communities, including aquatic ecologists, urban water system engineers and managers, as well as information and communications technology professionals and computer

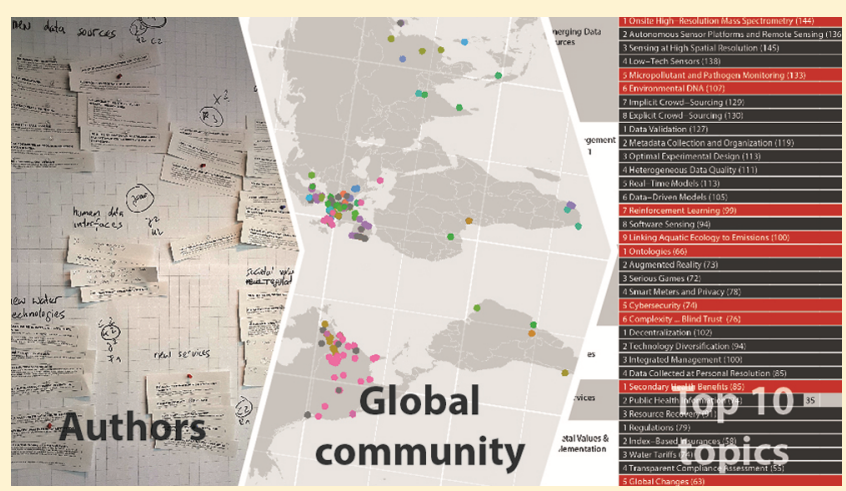
scientists. Activities in topics that are identified as novel will either require (i) cross-disciplinary training, such as importing new developments from the IT sector, or (ii) research in new areas for urban water specialists, for example, to help solve open questions in aquatic ecology. These results are, therefore, a call for interdisciplinary research beyond our own discipline. They also demonstrate that the water management community is not yet prepared for the digital transformation, where we will experience a data demand, i.e. a "pull" of urban water data into external services. The results suggest that a lot remains to be done to harvest the upcoming opportunities. Horizon scanning should be repeated on a routine basis, under the umbrella of an experienced polling organization.

\section{INEVITABLY CHANGING BOUNDARY CONDITIONS}

Today, urban water professionals often complain about a lack of timely information required for process design, operation, monitoring, and control. For example, site- and event-specific knowledge about pollutant load dynamics is sparse even though it is typical for concentrations in wastewater systems to span orders of magnitude between, and even within, dry and wet weather. This complicates the design of adequate monitoring programs. ${ }^{1-4}$ Fortunately, recent advances in information and communications technologies (ICT), 5,6 online sensors, ${ }^{7-10}$ and autonomous energy supplies ${ }^{11}$ make ubiquitous sensing of urban water systems economically viable today, even in remote and underground locations. Potentially, this would enable monitoring and management of water infrastructures ${ }^{12,13}$ and community health indicators, ${ }^{14}$ and, in turn, providing tangible information feedback to society. ${ }^{15}$

The provision of a new wealth of data however also poses many new questions. For example, sensor manufacturers and machine learning specialists promise substantial benefits of collecting and mining data in all industrial sectors, yet all too often leave out which exact challenges can be solved with these data (and which ones cannot). It is therefore possible that blockchain technology, ${ }^{16-19}$ reinforcement learning, and indexbased insurances are examples of solutions that are studied

Received: November 16, 2018

Revised: April 18, 2019

Accepted: June 7, 2019

Published: June 7, 2019 


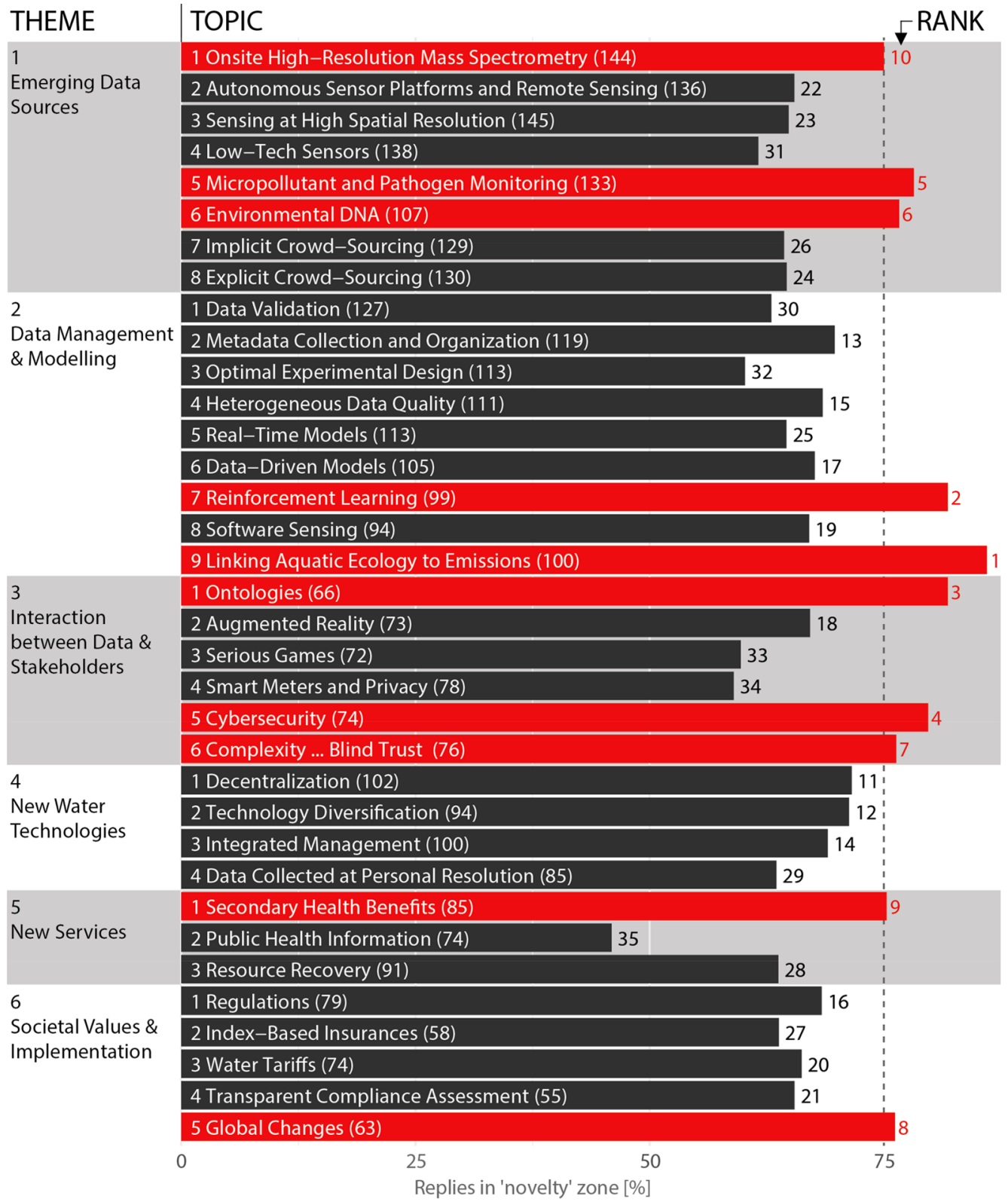

Figure 1. Ranking of topics according to novelty (i.e., importance $>$ familiarity, see subsection Data Analysis). The number in parentheses indicates the number of respondents per topic, the number at the end of the bar displays the rank.

intensively yet may never be matched with a problem to solve in the water sector. Furthermore, rapid expansion of digital data collection efforts gives rise to complex issues, for example, cybersecurity. ${ }^{12}$ Indeed, besides technological issues, a digitalized world will induce organizational and cultural changes. For example, machine-to-machine communication makes it possible for water utilities to pass the information it collects, for example, measured flow rates, to third parties in real time. It is, however, unclear whether the utilities of tomorrow will be prepared to use their flow meter data as a bargaining chip to negotiate access to other sources of information. We speculate that given the current period of expanding access to and creative chaos in digital technology, it becomes more important to identify what challenges such technology can and should solve. In other words, we believe that it is crucial to set well-calibrated and realistic goals before adopting and designing new algorithms to reach them. We address this with a horizon scan.
Various forms of horizon scanning have been applied to (i) support policy making, ${ }^{20,21}$ (ii) estimate market potential (e.g., advanced oxidation or online bacterial monitoring, ${ }^{22,23}$ ) and (iii) identify issues in other research areas (e.g., global conservation and biological diversity ${ }^{24}$ ). Greenblott et al. ${ }^{25}$ discuss different strategic foresight methods based on a survey from federal U.S. agencies. Two key findings appear particularly important to us: (1) Horizon scanning is the most commonly used foresight method for early detection of important developments. (2) Foresight work is more likely to be sustained if it is consistently supported by a central body. Scottish Water conducted a regional-scale horizon $\operatorname{scan}^{26}$ to support the development of future scenarios, covering topics such as global demographic and social trends, cybersecurity, the increasing pace of technological change, Internet-of-Things (IoT), and regulatory aspects. The horizon scan by Isle Utilities surveyed innovative technologies that use Artifical Intelligence (AI) for water and wastewater treatment and 
supply network management (personal communication; commercial report not publicly available). We conclude that horizon scanning is a well-established method for systematic screening of future societal trends ${ }^{27}$ and is, therefore, also useful to evaluate the risks and opportunities associated with ubiquitous sensing in the water sector.

We believe our horizon scan offers a timely look into the opportunities and threats for the water sector that are induced by ubiquitous sensing, emerging data sources, and associated techniques. It is ideally suited to prioritize objectives and adapt to upcoming changes in urban water management. Interestingly, the results of our study suggest that emerging topics for urban water will require an ever-more holistic approach, requiring expertise from aquatic ecology as well as IT and computer science. Therefore, we expect that interdisciplinary research will be essential to ensure that the digitalized world can deliver on the promises many of us envision.

\section{HORIZON SCANNING HELPS TO IDENTIFY CURRENT TRENDS AND FUTURE DEVELOPMENTS}

In contrast to many desktop horizon scans based on literature reviews, we used a multistage approach. We involved a diverse group of experts to evaluate it with a broad democratic process. Consequently, it delivers an overview that has a wider scope and reaches further than industry driven studies, which focus on specific technologies. $22,23,28$

Project Initialization. Our core group of seven authors defined the objective: "What are emerging topics related to data that are not yet widely known to the water professionals and could have substantial effects on the monitoring and/or management of urban storm- and wastewater systems?" Then, we proceeded as follows: (i) collection of topics $(n=38)$, (ii) curating topics into a final selection $(n=35)$ by eliminating overlapping topics, (iii) consulting the global community via an online survey (see below), also asking for additional topics, (iv) performing an intermediary workshop with an interdisciplinary expert panel, and (v) analysis of data.

Online Survey. The online survey (see Supporting Information SI 1) was designed to consult the global community about: (i) familiarity with a topic and (ii) importance of a topic, that is, impact on urban storm- and wastewater management. Additionally, for each topic, we formulated one possible future scenario, describing how a topic may manifest in the year 2030, here called Vision 2030. Indicators for (i) familiarity of a topic, (ii) importance of a topic, (iii) desirability of a scenario, and (iv) realism of a scenario were defined on a scale between 0 and 100 with 0 meaning complete disagreement and 100 complete agreement. Furthermore, we encouraged the respondents to suggest additional topics we may have missed and alternative scenarios. The survey was sent via e-mail on 22 August 2017 (reminder: 8 September 2017) to more than 2000 urban water professionals in different communities and mailing lists (see SI 2). Respondents were asked to provide answers for all topics if possible, but were also allowed to skip any theme.

Data Analysis. We defined novelty of an emerging topic as importance $>$ familiarity. To identify the top ten emerging topics, we calculated the percentage of answers per topic for which importance was higher than familiarity. We also identified the top ten emerging topics regarding importance only and the most feared Vision 2030 (i.e., "not desired" and "realistic"). Furthermore, we received 450 individual comments of which we deemed 124 of particular relevance (90 topic-specific; 22 new aspects; 12 on the survey methodology). We extracted three striking aspects that were mentioned repeatedly and, therefore, reflect a fairly common perception.

\section{DATA PUSH AND DATA DEMAND: ELICITING INFORMATION FROM THE GLOBAL URBAN WATER COMMUNITY}

Six Themes and 35 Topics. To prepare the online survey, the 35 emerging topics were grouped depending on thematic proximity into six distinct themes (see Figure 1): Themes 1-3 mainly include data push related topics, Themes 4-6 are mainly data demand driven. The data push topics are related to technological opportunities, such as miniaturization or lowpower sensor technology, models and modeling techniques, as well as hardware developments, for example, sensors that harvest the necessary energy of the environment. In contrast, the data demand topics reflect the societal needs for new data sources and efficient data streams, including previously unseen interactions between data and their users, services and societal values.

Theme 1, Emerging Data Sources, refers to the many opportunities and new insights provided by monitoring and management of storm- and wastewater systems (see SI 1 for a list of all themes and topics as presented in the online survey). The topics of Theme 2, Data Management and Modeling, focus on the availability of new tools that can convert the increasing amount and diversity of data into relevant information. Theme 3, Interaction between Data and Stakeholders, merges the topics related to the need of specialized tools to organize, optimize, and adapt system understanding. The topics of Theme 4, New Water Technologies, cover new process concepts and designs that can significantly contribute to an increased adaptive, intelligent, and resilient operation of storm- and wastewater systems. Theme 5, New Services, clusters the topics associated with new objectives that go beyond the traditional objective of storm- and wastewater systems. Theme 6, Societal Values and Implementation, focuses on the fact that data are easier to access, exhibit better quality, and cover a wider range of relevant parameters than before. It also considers topics that have the potential to improve the governance of urban water systems and allow societies to pursue their values more effectively and efficiently.

Community Response. We received a satisfactory response with 118 completed and 191 partly completed surveys (see SI 3). The complete responses came mainly from the academic sector (60\%) followed by consultants $(20 \%)$ and utilities (15\%); manufacturer, government, and students represent altogether less than 5\% (see Figure SI 2.1). Europe (67\%) and North America (21\%) dominated the responses, only few were from South America, Africa, and Australasia. The respondents' professional experience in the urban water field was larger than 10 years for $71 \%$ of the responses (larger than 5 years for 98\%). The number of respondentsconsidering partly and completely filled surveys-that answered both familiarity and importance per topic can be seen in Figure 1: it ranges from 144 (Onsite High-Resolution Mass Spectrometry (HRMS)) to 66 (Ontologies). Interestingly, the results suggest a drop in responses for themes 3 and 6. This will be discussed later (see Section 4).

The 10 Most Novel Topics. The top ten emerging topics can be seen in Figure 1. For these topics more than $75 \%$ of replies were in the novelty zone, that is, where importance was rated higher than familiarity. Subsequently, the ten emerging 
topics and examples of potential impact are shortly described by order of novelty:

Linking Aquatic Ecology to Emissions. Global transition, which is visible through increasing urbanization, migration patterns, and climate change, strongly influences the ecological conditions of streams in urban areas. An adequate management which integrates catchment and wastewater-related aspects is essential to mitigate these impacts. ${ }^{29,30}$ In practice, however, urban storm- and wastewater management is typically regulated based on norm-referenced physicochemical (nutrient and pollution loads) and hydraulic emission standards. Conceptually, this stands in contrast to the assessment of the ecological status of water bodies, which is primarily based on biotic indicators, that is, receiving water type-specific models for aquatic fauna and flora. These indicators reflect the impact of complex exposure patterns in an integrative manner, both over space and time. ${ }^{31,32}$ The mechanistic understanding of exposure to storm- and wastewater and its effects on biota has improved substantially in recent years. ${ }^{31,33-37}$ Despite such advances, it remains difficult to bridge the gap between ecological and engineering performance indicators. In addition, the involved stakeholders often remain isolated in their domain silos. Efforts across disciplines are limited and clear quantitative cause-effect-relationships between various (urban drainage) stressors and biological indicators are missing, often due to the lack of adequate data. The ecotoxicological relevance of sediments has been emphasized in recent studies. $^{38}$ The limited understanding of emergence and characteristics of "urban" suspended solids (concentration and size distribution dynamics, contaminant loading), and its contribution to detrimental effects on aquatic organisms calls for further research. To what extent are cocktails of trace pollutants in stormwater discharges relevant? How does this translate into design principles and performance assessment of treatment structures? New monitoring techniques (e.g., onsite HRMS, passive sampling, eDNA), generally more consistent and integral data sets, harmonized indicator metrics, and a cross-sectoral thinking may serve as enablers for a continued discussion.

Reinforcement Learning. Identifying the rules to control a complex system to achieve a (long-term) objective is a very difficult task. Traditionally, such rules are derived from deep or extensive system understanding. Models of the system may be used to validate and refine the rules. In contrast, Reinforcement Learning (RL) aims to avoid this manual procedure. It is a generic approach designed to automatically devise a good decision policy or control strategy. RL effectively adjusts the decision-making process by trial-and-error, often requiring a large number of exploratory actions followed by observing the obtained reward. Recent developments in combining artificial neural networks and RL (so-called Deep RL) showed very good performance for a variety of different systems (e.g. ${ }^{39}$ ). To apply RL to urban water management the definition of a reward function (e.g., minimize pollutant emissions) and the availability of a system model ${ }^{40}$ is required. The latter is needed as the algorithm cannot "play" with the real system to learn about it. RL can potentially replace many engineering heuristics of daily operation, leading to better system performance, and the possibility to easily change the control strategy to respect new regulations or scientific findings. However, defining a reward function that reflects the subjective preferences of multiple objectives will remain challenging (e.g., ref 41). For example, how should we trade off energy savings to achieve climate-neutrality against increased pollutant loads? Furthermore, any model used for training must be considered with some skepticism as one is typically unsure how modelreality mismatch would influence the operation of the real system, especially when the optimal policy can bring the system close to its operational or safety constraints.

Ontologies. Ontology-based solutions to decision-making stem from research in $\mathrm{Al}$, in particular the section focused on reasoning and logic. ${ }^{42}$ This generally requires two elements. ${ }^{43}$ The first element is the ontology, which is defined as a systematic representation of the available knowledge for a particular domain, for example, urban water management. Second, the construction of an artificial reasoner, that is, a computer-based algorithm that successfully deploys the knowledge available to make autonomous decisions or suggestions to an expert user. Most often, the available knowledge is represented with graphs, for example, as a semantic web. Constructing and maintaining such graphs for long-term use and reuse however remains an ongoing challenge. ${ }^{44}$ Successfully developing the second element is possibly even harder. Indeed, a general-purpose knowledgebased problem solver is not on the horizon yet. Despite the early stage of this research, early applications of ontology-based model choice ${ }^{45}$ and decision-making ${ }^{46}$ demonstrate the potential of the symbolist approach.

Cybersecurity. The increasing digitalization of the urban water system poses several challenges for its security. Cybersecurity in particular remains a novel aspect for most water professionals in the field today. While the monitoring capabilities offered by the IoT will greatly improve the decision-making process for design, operation, and control, this will only be realized if the data produced by and sent to devices can be trusted with very high reliability. Several disastrous scenarios can be conceived. A rather simple one consists of malicious agents aiming to disturb an urban water infrastructure by causing temporary or permanent damage in such a way that human safety or environmental safety is threatened. ${ }^{47}$ A more subtle scenario consists of malicious agents tampering data in such a way that human operators are triggered to make an erroneous decision. ${ }^{48}$ For example, an ill-informed enactment of emergency responses can cause large economic damage and suspension of public support for disaster prevention and management systems or lack of trust in first responders in emergency situations. ${ }^{49}$ An often overlooked threat to critical infrastructure is information warfare, which can quickly disrupt economic and communication infrastructure and, through disinformation, prevent accurate communication to the public during a crisis. ${ }^{50}$ Advances in machine learning will make it difficult to distinguish between real and falsified audio, video, or online personalities. ${ }^{51}$ Attackers can use these technologies to target critical infrastructures more rapidly and efficiently. Clearly, cybersecurity is not only critical to the management of existing infrastructure but also to ensure that the urban water infrastructure, which has demonstrably saved and improved lives over decades, remains a highly regarded asset by the citizens living in urban areas.

Complexity: Blind Trust. The increasing number of measurements in urban water system leads to a large amount of data. This may overwhelm human operators but at the same time it allows for more flexible and efficient systems through automating many operational tasks. One can easily imagine that automated solutions relieve, or even replace, humans in 
normal daily operation. However, if very rare incidents or technical failures occur, automated solutions may fail and human intervention will still be required. This needs operators with reliable expertise to operate such systems. Such expertise, often in the form of intuition and deep understanding, becomes more difficult to acquire when a system is automatically operated most of the time, due to the lack of training opportunities in realistic circumstances. This has been studied extensively in the context of aviation and driver assistance systems. ${ }^{52-54}$ Lessons that must be transferred to urban water systems are that an automated system must be able to "ask for help" long before the "safe zone of operation" is left and human operators must have the ability and confidence to overrule autonomous systems when required. In the aviation sector, several strategies are deployed ranging from fully autonomous control systems with humans needing to get permission to obtain control authority, to systems which only provide recommendations to the human pilot. ${ }^{55}$ The exact choice often depends on company culture and type of airplane. Moreover, commercial airplanes are equipped with multiple control systems, providing a smooth change between the associated flight modes. How control authority and graceful degradation in control performance are best implemented in the context of urban water systems remains unclear. A further challenge may be that the staff in a remote control management room not rely at all on their sensory experiences (e.g., feeling, smelling, hearing) unlike on-site managers and technicians today.

Micropollutant and Pathogen Monitoring. Public awareness of future human health concerns caused by micropollutants and pathogens is growing rapidly. ${ }^{56}$ Increasingly sensitive and automated high-throughput analytical methods ${ }^{57}$ will have to be developed to quantify an ever growing number of micropollutants (see also topic "Onsite HRMS") and pathogens, for example, by online flow cytometry, in (waste)water. Application of these new technologies will provide ubiquitous data at high spatiotemporal resolution to better understand occurrence and fate of (mixtures of) micropollutants and the changing nature of pathogens (e.g., multiresistant species). This will facilitate better protection of human and ecosystem health. Finally, the large scale implementation of advanced wastewater treatment technology to abate these micropollutants and pathogens for environmental protection and (in)direct potable reuse brings about large investments in countries such as the U.S., ${ }^{58}$ Switzerland, ${ }^{59}$ China, ${ }^{60}$ Canada, ${ }^{61}$ Sweden, ${ }^{62}$ The Netherlands, ${ }^{63}$ and more. Effectively assessing performance asks for highfrequency effluent monitoring to ensure that the discharges comply with effluent permits.

Environmental DNA (Biomonitoring of Natural and Engineered Aquatic Systems Using Environmental DNA $(e D N A))$. Biological organisms in aquatic systems can indicate ecosystem health, the presence/absence of specific pollution or changing environmental conditions. In the future, challenges regarding the occurrence, the abundance and the biodiversity of species could be overcome by applying environmental DNA (eDNA) methods. First, using eDNA in monitoring aquatic systems could provide standardized methods across different taxa, which would provide more accurate data. ${ }^{64,65}$ Second, the data would be more complete, because eDNA is less prone to missing populations with low densities or rare species. For urban drainage systems, eDNA could improve identifying illicit connections in stormwater systems ${ }^{66-69}$ by tracking fecal pollution from humans, or closely monitor combined sewer discharges at an unprecedented temporal resolution. For WWTPs, profiling entire microbial communities could lead to gain better insight into relevant processes, for example, bulking and foaming, ${ }^{70}$ digester performance, ${ }^{71}$ or the behavior of viruses. ${ }^{72,73}$ For receiving waters, eDNA can be useful through the spatial integration of point samples and the possibility to perform biomonitoring and chemical analysis on the same water sample. This would greatly improve tracking the impact of pollutant discharges or change in aquatic species. ${ }^{74}$ The development of portable and real-time capable instruments ${ }^{71}$ could even open up next generation compliance schemes and inform novel conservation strategies. ${ }^{75}$

Increasing Risk of Global Transition Which Could Disrupt the Performance of Urban Wastewater Systems. Urban water systems are mainly influenced by the behavior of the serviced population. Further important drivers are (i) policies and treatment standards, (ii) organizational requirements, (iii) treatment technologies, (iv) prices of inputs such as energy or chemicals, and ( $\mathrm{v})$ the value of outputs produced, such as nutrients for fertilizer use. Recent studies emphasize that fundamental changes in population size and other drivers occur on much smaller time-scales than the long physical life expectancy of inflexible infrastructures. ${ }^{76}$ Disruptive population changes can be caused by large-scale migration, for example, from civil conflicts over failure of climate change mitigation to socio-economic changes. Also, the risk of a deadly pandemic is increasing as new diseases emerge and spread faster and further because of increased mobility, air traffic, and urbanization. ${ }^{77}$ On a global level, the most important risks identified by the Global Risks Perception Survey ${ }^{78}$ all concern the performance of urban water systems, specifically (i) extreme weather events, (ii) failure of climate change mitigation and adaptation, and (iii) water crises, that is, "a significant decline in the available quality and quantity of fresh water". In addition, these are strongly interconnected with other important risks, such as conflict and migration, which contribute to increasing both their likelihood and impact.

Secondary Health Benefits. The primary health benefits of the urban water infrastructure (reduction of water-borne diseases, protection from extreme weather events) are selfunderstood nowadays (e.g. ref 79). In recent years, researchers have also become more aware of additional, secondary health benefits that the urban water infrastructure can provide. Stormwater in particular could be managed by multifunctional "green infrastructure" (e.g., a retention pond that is an integrated part of a recreational area). As many studies report a positive effect of urban green areas on physical and mental health (e.g., refs 80 and 81 ) such solutions may be preferable over traditional "grey infrastructure". Current water management planning approaches already consider a broad range of goals, such as drainage of stormwater, flood protection, and environmental impacts on receiving water bodies. ${ }^{82}$ More holistic planning approaches that also consider secondary healthy benefits in decision-making may lead to more sustainable solutions. ${ }^{83}$

Onsite High-Resolution Mass Spectrometry (HRMS). In almost every aquatic system, a selection of organic micropollutants is subject to important dynamics. Infrequent grab samples or composite samples are likely to not detect or underestimate relevant dynamics and peaks. Traditional or surrogate parameters can already be measured at high temporal resolution (e.g. refs 57 and 84) and demonstrate the gain of 
Table 1. Final Ranking of Topics According to Novelty, Importance for Urban Storm- and Wastewater Management and Most Feared Manifestation ${ }^{a}$

\begin{tabular}{|c|c|c|c|}
\hline rank & novelty & importance & most feared visions 2030 \\
\hline 1 & linking aquat. ecology to emiss. (2.9) & integrated management (4.3) & global changes $(6.5)$ \\
\hline 2 & reinforcement learning $(2.7)$ & data validation $(2.1)$ & augmented reality (3.2) \\
\hline 3 & ontologies (3.1) & regulations $(6.1)$ & serious games $(3.3)$ \\
\hline 4 & cybersecurity $(3.5)$ & resource recovery $(5.3)$ & complexity - blind trust $(3.6)$ \\
\hline 5 & micropoll. and pathogen monitoring (1.5) & decentralization $(4.1)$ & cybersecurity (3.5) \\
\hline 6 & environmental DNA (1.6) & real-time models (2.5) & index-based insurances (6.2) \\
\hline 7 & complexity - blind trust (3.6) & cybersecurity $(3.5)$ & explicit crowd-sourcing (1.8) \\
\hline 8 & global changes $(6.5)$ & metadata coll. and organization (2.2) & software sensing $(2.8)$ \\
\hline 9 & secondary health benefits (5.1) & linking aquat. ecology to emiss. (2.9) & data coll. at personal resol. (4.4) \\
\hline 10 & onsite high-res. mass spec. (1.1) & secondary health benefits (5.1) & smart meters and privacy (3.4) \\
\hline
\end{tabular}

new scientific and site-specific understanding. Subhourly micropollutant measurements over extended periods directly in the field will facilitate the identification of sources and understanding of fate for thousands of chemicals. Scientific and regulatory applications of target analyses and nontarget screening encompass for example: monitoring of pesticides in creeks, characterization of industrial discharges, quantification of combined sewer overflows, performance of advanced wastewater treatment processes, identification of illegal spills, and accidents. The leap forward-as, for example, for gaseous measurements with (trans)portable mass spectrometers (e.g. ref 7)-requires miniaturization of equipment and development of robust workflows, including real-time sample transfer, automated measurement, data evaluation and online transmission. ${ }^{85}$ See also the Micropollutant and Pathogen Monitoring section.

\section{UNDERSTANDING THE COMMUNITY RESPONSE}

We analyzed the following aspects to structure the wealth of survey entries, to consolidate and interpret results, and to make suggestions for future horizon scans in this field:

- Novelty, defined as 'more important than familiar' are considered emerging topics;

- Importance, irrespective of "familiarity";

- Feared visions, defined as undesirable yet likely to happen;

- Respondents' individual comments;

- Methodological improvements.

Novel Topics May Require Additional Efforts to Become Reality. Our main focus was on the topics that the community considers important but that may require additional efforts to become a reality; these correspond to the novel topics (see the top ten novel topics in Figure 1, Table 1). Certain topics, especially those of Themes 4 New Water Technologies, 5 New Services, and 6 Societal Values and Implementation, seem currently on the radar of the survey audience. Therefore, one should expect a lot of activity in the near-term with consolidated solutions available by 2030. On the other hand, some topics, like Ontologies (3.1), seem to be new to the urban water field as it appears highly ranked as a novel topic but it is not ranked as one of the 10 most important topics. In this case, only a relatively small effort on the further development of this topic is expected in the near future and the question "Is it worth investing in Ontologies to improve urban water management?" remains open. Another interesting outcome of the top ten novel topics is Linking Aquatic Ecology to Emissions (2.9). This is a well-known topic among research and practice communities but it is still considered novel by the survey audience and also in the top ten important topics. So, what can this mean? Possible explanations are that (i) there is need for further research in the topic (not enough knowledge); or (ii) there is a lack of interest in the topic because it is too difficult to be addressed with the data and tools currently available (also leading to lack of knowledge).

Many Important Topics Are Already Being Addressed. Also worth noting are those topics that are considered important by the community. Theme 2 Data Management and Modeling is the theme with a larger number (four) of topics in the importance ranking, whereas there are no topics from Theme 1 Emerging Data Sources. There are notable differences among the top ten of the Novelty and Importance rankings. Some of the important topics are already being addressed and, therefore, do not appear in the top ten novel topics. As an example, we can see Topics 4.1 Decentralization and 4.3 Integrated Management which are increasingly gaining momentum in the wastewater community. ${ }^{86-88}$ Topic 3.5 Cybersecurity is the only topic that appears in the top ten positions of both rankings, and among the most feared visions. This may indicate that Cybersecurity is a new (lack of knowledge) and important topic in the urban water field with relatively little work conducted so far.

Fear about Global Transitions and Interactions between Data and Stakeholders. Five out of the 10 most feared visions (right column in Table 1 and SI 4) are topics from Theme 3 Interaction between Data and Stakeholders. Data collection at personal level, the related loss of privacy as well as risks attributed to cybersecurity and/or fully automated systems are perceived as undesired but likely to occur, which somewhat reflects broader societal debates today. The expressed uneasiness regarding Theme 3 is furthermore reflected through (i) individual comments from the community (see next paragraph) and (ii) the respondents' behavior. For the latter, a distinct drop of approximately $25 \%$ in the number of "complete responses" for Theme 3 topics is observed, which we attribute to a dystopia-like perception (see details in SI 3, Figure SI 3.1). In particular, the uncertainty regarding Global Changes (6.5) and how it may affect urban water management is perceived as threat. Still, global transitions, as is Blind Trust vs Complexity (3.6) and Cybersecurity (3.5), are at the same time considered novel 
and emerging (cf. right and left column in Table 1). Although the topics which rank high in feared visions may be unappealing, we believe they are particularly relevant. First, because the potentially strong negative impact requires that the community develops a better understanding of both the involved risks and the implications of suitable mitigation measures. Second, suitable partners need to be identified to achieve cross-disciplinary knowledge exchange in the future.

Individual Comments Reveal Overarching Challenges. The analysis of more than 450 individual comments (see SI 5) revealed three main aspects. First, there is a large but fuzzy discomfort with regard to a potential data misuse through violation of privacy, confidentiality, and security standards, potentially triggered through precedents from data breaches in other sectors. Corresponding "visions" are rather perceived as undesirable threats, for example, that personspecific data could be exploited for unethical purposes. Interestingly, these concerns are often vague and seem to be mostly driven by the uncertainty of future (not only technological) developments. Whereas this can be interpreted as "lack of confidence" in the own ability (and/or capacity) to drive and control these developments, it also underlines the relevance of an adequate Interaction between data and stakeholders (Theme 3) in the light of emerging data sources.

Second, the participants' comments reveal a tendency toward an improved stewardship of existing data rather than solely counting on "brute force" sensor deployment. This, to some extent, indicates a mind-set within the community to keep the balance between considering existing (data) resources and exploiting emerging data collection opportunities. In this context, standardized measurement and open-source data validation protocols are perceived as beneficial, if not required.

Third, automation is considered as increasingly relevant across various levels and domains. At the same time, "losing control authority" is perceived as a very undesirable scenario but likely to occur. Blind trust in fully automated, self-learning approaches is not wanted (caveat: Keep the artificial intelligence under supervision by human agency). Proposed visions, which triggered such concerns, are responded with suggestions like conduct precursory risk analyses, have options to manually interact (air gaps), integrate expert knowledge, and investigate human-technology interference.

Improvements for Future Surveys. The result of the current horizon scan appears biased because of the rather homogeneous group of respondents and their professional background. Although the participants stem from a broad range of different institutions in the urban water field, such as universities, regulators and authorities, utilities and consultancies, the vast majority of respondents have an engineering background. While the affiliation of respondents to a particular sector (academic/nonacademic) is not reflected in the response preference (see SI 6, Figure SI 6.1), we believe that adapting the survey's dissemination strategy to reach potential respondents with professional backgrounds in social science, management, or ecology will lead to more objective results.

The thematic proximity and interdependence of some topics, such as Topic 1.3 and 1.4, is obvious. In the current horizon scan, this is an outcome of the structured process and thus maybe inevitable. In a similar fashion, the results are rather heterogeneous regarding quality, impact, and hierarchical level, among other things, because some topics are more difficult to grasp than others. In order to see whether thematic proximity affects the ranking of correspondents' responses- most importantly for the topics ranked top ten-we correlated response scores topic-by-topic $(35 \times 35)$ resulting in 595 pairs. The results show that the responses to questions regarding "familiarity" and "importance" are uncorrelated; especially for the top ten topics (see details in SI 7). The selection of the 10 most emerging topics remains unaffected. While we are convinced that the majority of the topics will appear in future horizon scans, particularly the topics in Themes 1 and 2 should be reviewed and consolidated.

A limitation of the survey is the narrow geographic distribution of respondents. Most of the questionnaires were filled in by wastewater professionals from Europe and North America. With very little return from Eastern Europe or Asia, it does not permit a representative global assessment. On the other hand, for the given sample the response preference is, geographically seen, rather homogeneous. A continent-specific analysis (North America, Europe, other continents) shows only marginal differences in the mean response preference (see SI 6, Figure SI 6.2). Still, future foresight studies should carefully disseminate survey announcements to obtain a geographically balanced feedback for more representative results.

To improve the completion rate and avoid the observed dropouts (see SI 3, Figure SI 3.1), the visions could be formulated more realistically and in a less pessimistic fashion. Also, for a survey that takes respondents up to $1 \mathrm{~h}$ to complete and leave comments, a random order of themes may have led to a more equal response rate across themes.

Although we still consider the separate elicitation of familiarity and importance a methodological improvement over, ${ }^{89}$ the two variables are probably not entirely independent. For example, how can a respondent consider a topic to be important when not being familiar with it? Similarly, one believes that a respondent is familiar with a topic when having hands-on experience, such as applying reinforcement learning methods to a real-world problem. Others think they are familiar if they read an introductory article on the topic. Here, we assume that (i) respondents have enough expertise in the field and (ii) the specific visions we provided are sufficient for a reasonably standardized assessment.

Finally, the ranking of the topics is not always very robust, that is, the ranking should not be considered on cardinal scale, for example, because the distances between first and second are not the same as between fifth and sixth. Although the ranking is based on a quantitative assessment, topics ranked 2-5 score almost equally, and hence one cannot be seen more relevant than another. The robustness could be assessed by identifying clusters through discontinuity points $(1 ; 2-5 ; 6-10 ; 11-35)$. However, horizon scans are foresight instruments and thus provide a qualitative rather than a quantitative insight anyway.

\section{KEY PRIORITIES AND FUTURE FORESIGHT STUDIES}

Linking Emissions and Aquatic Ecology. Interestingly, the results suggest that a rather classical problem is still considered to be novel in the sense that the academic and professional communities consider it important but are still not familiar with it. This is clearly a plea to intensify research efforts at the interface of urban water engineering and aquatic ecology.

Considering Push and Pull Drivers. Urban water management should prepare for both push and pull aspects of urban water data. In our view, the revolutionary aspect of 
the modern digitization is 2-fold: First, external data is now less costly and ubiquitously available, that is, information on important boundary conditions such as population estimates/ behavior, weather, etc., will be pushed through the Internet into SCADA systems and wastewater services. Second, other entities will be more interested in urban water data. In the future, we may obtain requests to "pull" urban water management data into external applications, simply because they contain valuable information on societal behavior. ${ }^{90-92}$

Increasing Data Availability Is Challenging. We infer two main points: first, there is a realistic possibility to literally "drown" in data, especially if data management tools are not up to the task regarding quality checks and filtering out unreliable information. Many methods are available from data science, and the community seems to be familiar with them on a theoretical level. In practice, we observe that developed capacities are not sufficient to harvest their full potential. Transparent and standardized data treatment protocols may help to achieve this. Second, data are not necessarily valuable in itself, and the community has to invest more effort to define quantitative goals, asking the right questions to be answered through data.

Future Developments Are Path-Dependent. For example, the deployment of Transparent Compliance Assessment using the blockchain technology (e.g., refs 16-19 see also description of topic 6.4 in SI 1) depends on the evolution of this particular technology itself. While the high energy demand is a clear technological bottleneck that may prevent a wider distribution, it is currently unclear whether regulation might curtail or boost this technique, as observed in some national legislation. ${ }^{93}$ Key would be to actively follow current trends, to critically evaluate if trends allow to really advance knowledge in the domain, and to shape emerging techniques to facilitate sustainable urban water management.

Two Main Future Perspectives. First, the results suggest that more and more topics will become relevant, especially on the interface of wastewater engineering with ICT and ecological applications. As we cannot be experts in all novel topics, for us this is a clear call for more interdisciplinary collaborations. We also have to think how to include the relevant skills in the urban water community curriculum. Second, the ongoing digitization not only brings about technological change, but requires organizational adjustments, too. Similar as with photography, where backing up digital images has become more relevant than copying analog images, utilities now have to think about new archiving and reporting processes. $^{94,95}$

Future Horizon Scanning. The positive feedback received from the community suggests that Horizon Scanning is a useful exercise. The current horizon scan could be the starting point of dedicated surveys among professionals in the water sector. Sutherland et al. ${ }^{89}$ are doing this type of horizon scan on a regular basis in the ecological community for several years. After almost a decade, they are able to identify a positive impact with the chance to review community perception and extract a lead opinion. Considering the diversity of the topics put up for discussion, further input from representatives of social and economic sciences, computer scientists but also political stakeholders would be valuable and should be considered for the next edition of this horizon scan. While we clearly support the idea of repeating this horizon scan in the future, we suggest doing so under the umbrella of a professional entity, such as the International Water Association or the Water Environment Federation. Having an independent institution taking over the stewardship of such initiative could improve the response of the community and ensure a more representative survey.

\section{ASSOCIATED CONTENT}

Supporting Information

The Supporting Information is available free of charge on the ACS Publications website at DOI: 10.1021/acs.est.8b06481.

SI 1, Online Survey; SI 2, Participants and summary statistics; SI 3, Response behavior of respondents; SI 4, Responses for scenarios Vision 2030; SI 5, Summary of comments from survey; SI 6, Responses for importance and familiarity; SI 7, Correlation analysis to discuss thematic proximity; SI 8, Database with all responses (PDF)

\section{AUTHOR INFORMATION}

\section{Corresponding Author}

*E-mail: christoph.ort@eawag.ch.

ORCID $\odot$

Frank Blumensaat: 0000-0002-0742-7950

Christoph Ort: 0000-0001-9950-2286

Kris Villez: 0000-0002-8330-010X

\section{Author Contributions}

This study is the result of a joint and long-term effort of a group of water researchers with different backgrounds and at different levels of expertise. Authors are listed in strict alphabetical order to reflect the fact that all authors contributed equal shares to this work.

\section{Notes}

The authors declare no competing financial interest.

\section{ACKNOWLEDGMENTS}

The voluntary contribution of almost 200 members of the urban wastewater community is appreciated greatly and the Eawag group leaders that lend themselves to a focused interview regarding their views on the future of ubiquitous sensing are thanked wholeheartedly. Similarly, we show our appreciation to the over 50 participants of an interdisciplinary workshop held at Eawag, where valuable feedback was obtained regarding the first interpretation of the survey results. We express our gratitude to Liliane Manny for contributing to the design of the online survey. Finally, we thank the two anonymous reviewers for their valuable comments. Peter Vanrolleghem holds the Canada Research Chair in Water Quality Modelling. This work was the fruit of a short-term targeted sabbatical stay of Peter Vanrolleghem as an Eawag Proto-Synthesis visitor.

\section{REFERENCES}

(1) Khan, S.; Lau, S.-L.; Kayhanian, M.; Stenstrom Michael, K. Oil and Grease Measurement in Highway Runoff-Sampling Time and Event Mean Concentrations. J. Environ. Eng. 2006, 132 (3), 415-422.

(2) Lepot, M.; Aubin, J.-B.; Bertrand-Krajewski, J.-L. Accuracy of different sensors for the estimation of pollutant concentrations (total suspended solids, total and dissolved chemical oxygen demand) in wastewater and stormwater. Water Sci. Technol. 2013, 68 (2), 462471.

(3) McCarthy, D. T.; Zhang, K.; Westerlund, C.; Viklander, M.; Bertrand-Krajewski, J.-L.; Fletcher, T. D.; Deletic, A. Assessment of 
sampling strategies for estimation of site mean concentrations of stormwater pollutants. Water Res. 2018, 129, 297-304.

(4) Ort, C.; Lawrence, M. G.; Rieckermann, J.; Joss, A. Sampling for pharmaceuticals and personal care products (PPCPs) and illicit drugs in wastewater systems: Are your conclusions valid? A critical review. Environ. Sci. Technol. 2010, 44 (16), 6024-6035.

(5) Ebi, C.; Schaltegger, F.; Rüst, A.; Blumensaat, F. Synchronous LoRa Mesh Network to Monitor Processes in Underground Infrastructure. IEEE Access 2019, 7, 57663-57677.

(6) Blumensaat, F.; Ebi, C.; Dicht, S.; Rieckermann, J.; Maurer, M. Langzeitüberwachung der Raum-Zeit- Dynamik in Entwässerungssystemen mittels Niedrigenergiefunk. KA: Korrespondenz Abwasser Abfall 2017, 64 (7), 594-603.

(7) Brennwald, M. S.; Schmidt, M.; Oser, J.; Kipfer, R. A Portable and Autonomous Mass Spectrometric System for On-Site Environmental Gas Analysis. Environ. Sci. Technol. 2016, 50 (24), 1345513463.

(8) Ledergerber, J. M.; Maruéjouls, T.; Vanrolleghem, P. A. Optimal experimental design for calibration of a new sewer water quality model. J. Hydrol. 2019, 574, 1020-1028.

(9) Vanrolleghem, P. A.; Lee, D. S. On-line monitoring equipment for wastewater treatment processes: state of the art. Water Sci. Technol. 2003, 47 (2), 1-34.

(10) Campisano, A.; Cabot Ple, J.; Muschalla, D.; Pleau, M.; Vanrolleghem, P. A. Potential and limitations of modern equipment for real time control of urban wastewater systems. Urban Water J. 2013, 10 (5), 300-311.

(11) Ferreira Carvalho, C. M.; Paulino, N. F. S. V. Energy Harvesting Electronic Systems. In CMOS Indoor Light Energy Harvesting System for Wireless Sensing Applications; Ferreira Carvalho, C. M., Paulino, N. F. S. V., Eds.; Springer International Publishing: Cham, 2016; pp 7-42.

(12) Eggimann, S.; Mutzner, L.; Wani, O.; Schneider, M. Y.; Spuhler, D.; Moy de Vitry, M.; Beutler, P.; Maurer, M. The Potential of Knowing More: A Review of Data-Driven Urban Water Management. Environ. Sci. Technol. 2017, 51 (5), 2538-2553.

(13) Zodrow, K. R.; Li, Q.; Buono, R. M.; Chen, W.; Daigger, G.; Dueñas-Osorio, L.; Elimelech, M.; Huang, X.; Jiang, G.; Kim, J. H.; Logan, B. E.; Sedlak, D. L.; Westerhoff, P.; Alvarez, P. J. J. Advanced Materials, Technologies, and Complex Systems Analyses: Emerging Opportunities to Enhance Urban Water Security. Environ. Sci. Technol. 2017, 51 (18), 10274-10281.

(14) Choi, P. M.; Tscharke, B. J.; Donner, E.; O’Brien, J. W.; Grant, S. C.; Kaserzon, S. L.; Mackie, R.; O’Malley, E.; Crosbie, N. D.; Thomas, K. V.; Mueller, J. F. Wastewater-based epidemiology biomarkers: Past, present and future. TrAC, Trends Anal. Chem. 2018, 105, 453-469.

(15) Signer, R., Prototype for urban system to detect and prevent sewage overflows. Design Observer 2011.

(16) Tapscott, D.; Tapscott, A. Blockchain Revolution: How the Technology Behind Bitcoin Is Changing Money, Business, and the World; Portfolio: New York, 2016; p 368.

(17) Weisbord, E. Blockchain: the final drop in the wave of digital water disruption, Part 2 URL: https://iwa-network.org/blockchainthe-final-drop-in-the-wave-of-digital-water-disruption-part-2/ (accessed: 2019-04-18), Archived by WebCite ${ }^{\circledR}$ at http://www. webcitation.org/77iq9HL7o, International Water Association, 2018.

(18) Niya, S. R.; Jha, S. S.; Bocek, T.; Stiller, B. Design and Implementation of an Automated and Decentralized Pollution Monitoring System with Blockchains, Smart Contracts, and LoRaWAN, IEEE/IFIP Network Operations and Management Symposium: Cognitive Management in a Cyber World, NOMS 2018, 2018; pp 1-4.

(19) Grigorik, I., Minimum Viable Block Chain. 2019-04-18. URL: https://www.igvita.com/2014/05/05/minimum-viable-block-chain/ (accessed 2019-04-18), Archived by WebCite ${ }^{\circledR}$ at http://www. webcitation.org/77imPIbe2, 2014.

(20) Schultz, W. L. The cultural contradictions of managing change: Using horizon scanning in an evidence-based policy context. foresight 2006, 8 (4), 3-12.
(21) van Rij, V. Joint horizon scanning: Identifying common strategic choices and questions for knowledge. Science and Public Policy 2010, 37 (1), 7-18.

(22) Bluetechresearch Advanced Oxidation Processes: Horizon Scan \& Competition Landscape Survey; May, 2017.

(23) Bluetechresearch Online Bacterial Monitoring-Horizon Scan and Competitive Landscape Survey, 2018.

(24) Sutherland, W. J.; Barnard, P.; Broad, S.; Clout, M.; Connor, B.; Côté, I. M.; Dicks, L. V.; Doran, H.; Entwistle, A. C.; Fleishman, E.; Fox, M.; Gaston, K. J.; Gibbons, D. W.; Jiang, Z.; Keim, B.; Lickorish, F. A.; Markillie, P.; Monk, K. A.; Pearce-Higgins, J. W.; Peck, L. S.; Pretty, J.; Spalding, M. D.; Tonneijck, F. H.; Wintle, B. C.; Ockendon, N. A 2017 Horizon Scan of Emerging Issues for Global Conservation and Biological Diversity. Trends in Ecology \& Evolution 2017, 32 (1), $31-40$.

(25) Greenblott, J. M.; O'Farrell, T.; Olson, R.; Burchard, B. Strategic Foresight in the Federal Government: A Survey of Methods, Resources, and Institutional Arrangements. World Futures Review 2018, 1946756718814908

(26) Water, S. Horizon Scanning Report 2016-identifying Future Drivers to Continue to Be Trusted to Serve (Supporting Document); Scottish Water, 2016.

(27) Cuhls, K.; Erdmann, L.; Warnke, P.; Toivanen, H.; Toivanen, M.; van der Giessen, A.; Seiffert, L. Models of Horizon Scanning - How to integrate Horizon Scanning into European Research and Innovation Policies; European Commission: Brussels, 2015.

(28) Williams, H.; Ringland, G. Horizon Scanning Report 2016Supporting Information; Scottish Water and SAMI Consulting, 2016.

(29) Bernhardt, E. S.; Palmer, M. A. Restoring streams in an urbanizing world. Freshwater Biol. 2007, 52 (4), 738-751.

(30) Paul, M. J.; Meyer, J. L. Streams in the urban landscape. Annu. Rev. Ecol. Syst. 2001, 32 (1), 333-365.

(31) Hering, D.; Moog, O.; Sandin, L.; Verdonschot, P. F. M. Overview and application of the AQEM assessment system. Hydrobiologia 2004, 516 (1), 1-20.

(32) Segner, H. Ecotoxicology - How to Assess the Impact of Toxicants in a Multi-Factorial Environment?. In Multiple Stressors: A Challenge for the Future; Springer: Netherlands, 2007; p 39-56.

(33) Berger, E.; Haase, P.; Schäfer, R. B.; Sundermann, A. Towards stressor-specific macroinvertebrate indices: Which traits and taxonomic groups are associated with vulnerable and tolerant taxa? Sci. Total Environ. 2018, 619 (620), 144-154.

(34) Furse, M.; Hering, D.; Moog, O.; Verdonschot, P.; Johnson, R. K.; Brabec, K.; Gritzalis, K.; Buffagni, A.; Pinto, P.; Friberg, N.; Murray-Bligh, J.; Kokes, J.; Alber, R.; Usseglio-Polatera, P.; Haase, P.; Sweeting, R.; Bis, B.; Szoszkiewicz, K.; Soszka, H.; Springe, G.; Sporka, F.; Krno, I. The STAR project: context, objectives and approaches. Hydrobiologia 2006, 566, 3-29.

(35) Hein, M.; Rotter, S.; Schmitt-Jansen, M.; von der Ohe, P. C.; Brack, W.; de Deckere, E.; Schmitt, C.; de Zwart, D.; Posthuma, L.; Foekema, E. M.; Muñoz, I.; Sabater, S.; Segner, H.; Semenzin, E.; Marcomini, A.; van Gils, J.; van Hattum, B.; van Vliet, L. A. MODELKEY - Key findings and recommendations for reaching the EU Water Framework Directive's quality objectives. Environ. Sci. Eur. 2010, 22 (3), 217.

(36) Manolakos, E.; Virani, H.; Novotny, V. Extracting knowledge on the links between the water body stressors and biotic integrity. Water Res. 2007, 41 (18), 4041.

(37) Walsh, C. J.; Waller, K. A.; Gehling, J.; Mac Nally, R. Riverine invertebrate assemblages are degraded more by catchment urbanisation than by riparian deforestation. Freshwater Biol. 2007, 52 (3), 574-587.

(38) Schweizer, M.; Dieterich, A.; Corral Morillas, N.; Dewald, C.; Miksch, L.; Nelson, S.; Wick, A.; Triebskorn, R.; Köhler, H. R. The importance of sediments in ecological quality assessment of stream headwaters: embryotoxicity along the Nidda River and its tributaries in Central Hesse, Germany. Environ. Sci. Eur. 2018, 30 (1), 22. 
(39) Arulkumaran, K.; Deisenroth, M. P.; Brundage, M.; Bharath, A. A. A Brief Survey of Deep Reinforcement Learning. IEEE Signal Processing Magazine 2017, 34 (6), 26-38.

(40) Castelletti, A., Galelli, S., Restelli, M.; Soncini-Sessa, R., Treebased reinforcement learning for optimal water reservoir operation. Water Resour. Res. 2010, 46, (9). DOI: 10.1029/2009WR008898

(41) Slovic, P. The Construction of Preference. Am. Psychol. 1995, 50, 364-371.

(42) Domingos, P. The Master Algorithm: How the Quest for the Ultimate Learning Machine Will Remake Our World, Reprint ed.; Basic Books: New York, 2018; p 352.

(43) van Ruijven, L. C. Ontology for Systems Engineering. Procedia Computer Science 2013, 16, 383-392.

(44) Vigo, M.; Bail, S.; Jay, C.; Stevens, R. Overcoming the pitfalls of ontology authoring: Strategies and implications for tool design. International Journal of Human-Computer Studies 2014, 72 (12), 835845.

(45) Gibert, K.; Sànchez, M. Improving ontological knowledge with reinforcement in recommending the data mining method for real problems. In Advances in Artificial Intelligence - 16th Conference of the Spanish Association for Artificial Intelligence (CAEPIA2015), 2015; pp 769-778.

(46) Ceccaroni, L.; Cortés, U.; Sànchez-Marrè, M. OntoWEDSS: augmenting environmental decision-support systems with ontologies. Environmental Modelling \& Software 2004, 19 (9), 785-797.

(47) Alibasic, A.; Junaibi, R. A.; Aung, Z.; Woon, W. L.; Omar, M. A. Cybersecurity for Smart Cities: A Brief Review. In Data Analytics for Renewable Energy Integration; Springer: Cham, 2016; pp 22-30.

(48) Giani, A.; Bitar, E.; Garcia, M.; McQueen, M.; Khargonekar, P.; Poolla, K. Smart Grid Data Integrity Attacks. IEEE Transactions on Smart Grid 2013, 4 (3), 1244-1253.

(49) Wray, R.; Rivers, J.; Whitworth, A.; Jupka, K. Public Perceptions About Trust in Emergency Risk Communication: Qualitative Research Findings. Int. J. Mass Emerg. Disasters 2006, 24 (1), 45-75.

(50) Allen, G.; Chan, T. Artificial Intelligence and National Security; Harvard Kennedy School: Cambridge, MA, July, 2017; p 132.

(51) Chen, A. The Agency; The New York Times, June 2, 2015.

(52) Billings, C. E. Human-Centered Aviation Automation: Principles and Guidelines, 1996.

(53) Merat, N.; Jamson, A. H.; Lai, F. C. H.; Daly, M.; Carsten, O. M. J. Transition to manual: Driver behaviour when resuming control from a highly automated vehicle. Transportation Research Part F: Traffic Psychology and Behaviour 2014, 27, 274-282.

(54) Sarter, N. B., Woods, D. D., Billingsand Charles, E., Automation surprises. In Handbook of Human Factors \& Ergonomics, 2nd ed., 1997; Vol. 2, pp 1926-1943.

(55) Markoff, J., Planes Without Pilots. The New York Times 2017/ 12/21/T05:41:18.072Z, 2017.

(56) Schwarzenbach, R. P.; Escher, B. I.; Fenner, K.; Hofstetter, T. B.; Johnson, C. A.; Von Gunten, U.; Wehrli, B. The challenge of micropollutants in aquatic systems. Science 2006, 313 (5790), 10721077.

(57) Rode, M.; Halbedel née Angelstein, S.; Anis, M. R.; Borchardt, D.; Weitere, M. Continuous In-Stream Assimilatory Nitrate Uptake from High-Frequency Sensor Measurements. Environ. Sci. Technol. 2016, 50 (11), 5685-5694.

(58) Oneby, M. A.; Bromley, C. O.; Borchardt, J. H.; Harrison, D. S. Ozone Treatment of Secondary Effluent at U.S. Municipal Wastewater Treatment Plants. Ozone: Sci. Eng. 2010, 32 (1), 43-55.

(59) Eggen, R. I. L.; Hollender, J.; Joss, A.; Schärer, M.; Stamm, C. Reducing the Discharge of Micropollutants in the Aquatic Environment: The Benefits of Upgrading Wastewater Treatment Plants. Environ. Sci. Technol. 2014, 48 (14), 7683-7689.

(60) Sui, Q.; Huang, J.; Lu, S.; Deng, S.; Wang, B.; Zhao, W.; Qiu, Z.; Yu, G. Removal of pharmaceutical and personal care products by sequential ultraviolet and ozonation process in a full-scale wastewater treatment plant. Front. Environ. Sci. Eng. 2014, 8 (1), 62-68.
(61) CCE, Montreal's Gigantic Sewage Treatment Plant Adds Ozone Disinfection; Canadian Consulting Engineer, 2015.

(62) Nilsson, F.; Ekblad, M.; la Cour Jansen, J.; Jönsson, K. Removal of pharmaceuticals with ozone at 10 Swedish wastewater treatment plants. Water Practice \& Technology 2017, 12 (4), 871-881.

(63) de Wilt, A.; van Gijn, K.; Verhoek, T.; Vergnes, A.; Hoek, M.; Rijnaarts, H.; Langenhoff, A. Enhanced pharmaceutical removal from water in a three step bio-ozone-bio process. Water Res. 2018, 138, 97-105.

(64) Deiner, K.; Fronhofer, E. A.; Mächler, E.; Walser, J.-C.; Altermatt, F. Environmental DNA reveals that rivers are conveyer belts of biodiversity information. Nat. Commun. 2016, 7, 12544.

(65) Li, F.; Peng, Y.; Fang, W.; Altermatt, F.; Xie, Y.; Yang, J.; Zhang, X. Application of Environmental DNA Metabarcoding for Predicting Anthropogenic Pollution in Rivers. Environ. Sci. Technol. 2018, 52 (20), 11708-11719.

(66) Cao, Y.; Raith, M. R.; Griffith, J. F. Droplet digital PCR for simultaneous quantification of general and human-associated fecal indicators for water quality assessment. Water Res. 2015, 70, 337349.

(67) Layton, B. A.; Cao, Y.; Ebentier, D. L.; Hanley, K.; Ballesté, E.; Brandão, J.; Byappanahalli, M.; Converse, R.; Farnleitner, A. H.; Gentry-Shields, J.; Gidley, M. L.; Gourmelon, M.; Lee, C. S.; Lee, J.; Lozach, S.; Madi, T.; Meijer, W. G.; Noble, R.; Peed, L.; Reischer, G. H.; Rodrigues, R.; Rose, J. B.; Schriewer, A.; Sinigalliano, C.; Srinivasan, S.; Stewart, J.; Van De Werfhorst, L. C.; Wang, D.; Whitman, R.; Wuertz, S.; Jay, J.; Holden, P. A.; Boehm, A. B.; Shanks, O.; Griffith, J. F. Performance of human fecal anaerobe-associated PCR-based assays in a multi-laboratory method evaluation study. Water Res. 2013, 47 (18), 6897-6908.

(68) Schiff, K., Griffith, J., Steele, J., Benjamin, A., Ercumen, A., Benjamin-Chung, J., Colford, J. M., Soller, J., Wilson, R.; McGee, C. The Surfer Health Study: A Three-Year Study Examining Illness Rates Associated with Surfing During Wet Weather; Southern California Coastal Water Research Project Authority: Costa Mesa, CA, 2016 (http://ftp.sccwrp.org/pub/download/DOCUMENTS/ TechnicalReports/943_SurferHealthStudy.pdf).

(69) Schiff, K.; Kinney, P. Tracking sources of bacterial contamination in stormwater discharges to Mission Bay, California. Water Environ. Res. 2001, 73 (5), 534-542.

(70) Jiang, X.-T.; Guo, F.; Zhang, T. Population Dynamics of Bulking and Foaming Bacteria in a Full-scale Wastewater Treatment Plant over Five Years. Sci. Rep. 2016, 6, 24180.

(71) Hardegen, J.; Latorre-Perez, A.; Vilanova, C.; Gunther, T.; Simeonov, C.; Porcar, M.; Luschnig, O.; Abendroth, C. Liquid cosubstrates repower sewage microbiomes. bioRxiv 2018, 261339.

(72) Lood, R.; Ertürk, G.; Mattiasson, B. Revisiting Antibiotic Resistance Spreading in Wastewater Treatment Plants - Bacteriophages as a Much Neglected Potential Transmission Vehicle. Front. Microbiol. 2017, 8. DOI: 10.3389/fmicb.2017.02298

(73) Prado, T.; Gaspar, A. M. C.; Miagostovich, M. P. Detection of enteric viruses in activated sludge by feasible concentration methods. Braz. J. Microbiol. 2014, 45 (1), 343-349.

(74) Deiner, K.; Altermatt, F. Transport Distance of Invertebrate Environmental DNA in a Natural River. PLoS One 2014, 9 (2), No. e88786.

(75) Bittel, J. How Scientists Use Teeny Bits of Leftover DNA to Solve Wildlife Mysteries; Smithsonian, 2017.

(76) Neumann, M. B.; Rieckermann, J.; Hug, T.; Gujer, W. Adaptation in hindsight: dynamics and drivers shaping urban wastewater systems. J. Environ. Manage. 2015, 151, 404-415.

(77) WHO Implementation of the International Health Regulations (2005) - Report of the Review Committee on the Role of the International Health Regulations (2005) in the Ebola Outbreak and Response, A69/ 21; Geneva, 2016/05/13/, 2016.

(78) WEF The Global Risks Report 2017; World Economic Forum: Geneva, 2017; Vol. 12, p 78. 
(79) Ferriman, A. BMJ readers choose the "sanitary revolution" as greatest medical advance since 1840. BMJ: British Medical Journal 2007, 334 (7585), 111.

(80) Lee, A. C.; Maheswaran, R.; R. The health benefits of urban green spaces: a review of the evidence. Journal of Public Health 2011, 33 (2), 212-222.

(81) Tzoulas, K.; Korpela, K.; Venn, S.; Yli-Pelkonen, V.; Kaźmierczak, A.; Niemela, J.; James, P. Promoting ecosystem and human health in urban areas using Green Infrastructure: A literature review. Landscape and Urban Planning 2007, 81 (3), 167-178.

(82) Lienert, J.; Scholten, L.; Egger, C.; Maurer, M. Structured decision-making for sustainable water infrastructure planning and four future scenarios. EURO J. Decis Process 2015, 3 (1), 107-140.

(83) Dreiseitl, H. Blue-green social place-making: Infrastructures for sustainable cities. Journal of Urban Regeneration \& Renewal 2015, 8 (2), 161-170.

(84) Kirchner, J. W.; Feng, X.; Neal, C.; Robson, A. J. The fine structure of water-quality dynamics: the (high-frequency) wave of the future. Hydrol. Processes 2004, 18 (7), 1353-1359.

(85) MS2field, an implementation example. URL http://www. eawag.ch/ms2field (accessed 2019-04-18), Archived by WebCite ${ }^{\circledR}$ at http://www.webcitation.org/77isaK5eI, 2019.

(86) Eggimann, S.; Truffer, B.; Maurer, M. To connect or not to connect? Modelling the optimal degree of centralisation for wastewater infrastructures. Water Res. 2015, 84, 218-231.

(87) Larsen, T. A.; Hoffmann, S.; Lüthi, C.; Truffer, B.; Maurer, M. Emerging solutions to the water challenges of an urbanizing world. Science 2016, 352 (6288), 928-933.

(88) Roefs, I.; Meulman, B.; Vreeburg, J. H. G.; Spiller, M. Centralised, decentralised or hybrid sanitation systems? Economic evaluation under urban development uncertainty and phased expansion. Water Res. 2017, 109, 274-286.

(89) Sutherland, W. J.; Broad, S.; Caine, J.; Clout, M.; Dicks, L. V.; Doran, H.; Entwistle, A. C.; Fleishman, E.; Gibbons, D. W.; Keim, B.; LeAnstey, B.; Lickorish, F. A.; Markillie, P.; Monk, K. A.; Mortimer, D.; Ockendon, N.; Pearce-Higgins, J. W.; Peck, L. S.; Pretty, J.; Rockström, J.; Spalding, M. D.; Tonneijck, F. H.; Wintle, B. C.; Wright, K. E. A Horizon Scan of Global Conservation Issues for 2016. Trends in Ecology \& Evolution 2016, 31 (1), 44-53.

(90) Daughton, C. G. Monitoring wastewater for assessing community health: Sewage Chemical-Information Mining (SCIM). Sci. Total Environ. 2018, 619-620, 748-764.

(91) Enfinger Kevin, L.; Mitchell Paul, S. Sewer Sociology-San Diego Metropolitan Area, Pipelines 2009, 2009.

(92) Ort, C.; van Nuijs, A. L. N.; Berset, J.-D.; Bijlsma, L.; Castiglioni, S.; Covaci, A.; de Voogt, P.; Emke, E.; Fatta-Kassinos, D.; Griffiths, P.; Hernández, F.; González-Mariño, I.; Grabic, R.; Kasprzyk-Hordern, B.; Mastroianni, N.; Meierjohann, A.; Nefau, T.; Ostman, M.; Pico, Y.; Racamonde, I.; Reid, M.; Slobodnik, J.; Terzic, S.; Thomaidis, N.; Thomas, K. V. Spatial differences and temporal changes in illicit drug use in Europe quantified by wastewater analysis. Addiction 2014, 109 (8), 1338-1352.

(93) Liechtenstein. Consultation launched on Blockchain Act, 2018.

(94) Gianella, S.; Gujer, W. Improving the Information Governance of Public Utilities Through an Organizational Knowledge Base; Mathew, J., Kennedy, J., Ma, L., Tan, A., Anderson, D., Eds.; Springer London, 2006; Vol. 2006, pp 406-417.

(95) Manny, L.; Fischer, M.; Rieckermann, J. Policy Analysis for Better Protection of Receiving Waters during Wet Weather. In 11th International Conference on Urban Drainage Modelling, Palermo, Italy, September 23-26, 2018. 